\title{
Prevalence and Correlates of Medical Financial Hardship in the USA
}

\author{
K. Robin Yabroff, Ph.D, Jingxuan Zhao, M.P.H, Xuesong Han, Ph.D, and \\ Zhiyuan Zheng, Ph.D
}

Surveillance and Health Services Research Program, American Cancer Society, Atlanta, GA, USA.

\begin{abstract}
BACKGROUND: High patient out-of-pocket (OOP) spending for medical care is associated with medical debt, distress about household finances, and forgoing medical care because of cost in the USA.

OBJECTIVE: To examine the national prevalence of medical financial hardship domains: (1) material conditions from increased OOP expenses (e.g., medical debt), (2) psychological responses (e.g., distress), and (3) coping behaviors (e.g., forgoing care); and factors associated with financial hardship.

DESIGN AND PARTICIPANTS: We identified adults aged $18-64$ years $(N=68,828)$ and $\geq 65$ years $(N=24,614)$ from the 2015-2017 National Health Interview Survey. Multivariable analyses of nationally representative crosssectional survey data were stratified by age group, 1864 years and $\geq 65$ years.
\end{abstract}

MAIN MEASURES: Prevalence of material, psychological, and behavioral hardship and hardship intensity.

KEY RESULTS: Approximately 137.1 million (95\% CI 132.7-141.5) adults reported any medical financial hardship in the past year. Hardship is more common for material, psychological and behavioral domains in adults aged $18-64$ years $(28.9 \%, 46.9 \%$, and $21.2 \%$, respectively) than in adults aged $\geq 65$ years $(15.3 \%, 28.4 \%$, and $12.7 \%$, respectively; all $p<.001)$. Lower educational attainment and more health conditions were strongly associated with hardship intensity in multivariable analyses in both age groups $(p<.001)$. In the younger group, the uninsured were more likely to report multiple domains of hardship (52.8\%), compared to those with some public $(26.5 \%)$ or private insurance $(23.2 \%)(p<.001)$. In the older group, individuals with Medicare only were more likely to report hardship in multiple domains (17.1\%) compared to those with Medicare and public (12.1\%) or Medicare and private coverage $(10.1 \%)(p<.001)$.

CONCLUSIONS: Medical financial hardship is common in the USA, especially in adults aged 18-64 years and those without health insurance coverage. With trends towards higher patient cost-sharing and increasing health care costs, risks of hardship may increase in the future.

The authors conducted the study as part of the intramural research program at the American Cancer Society.

Electronic supplementary material The online version of this article (https://doi.org/10.1007/s11606-019-05002-w) contains supplementary material, which is available to authorized users.

Received June 20, 2018

Revised December 10, 2018

Accepted March 15, 2019

Published online May 1, 2019
KEY WORDS: out-of-pocket spending; access to care; medical financial hardship; medical debt; prescription drug nonadherence; health insurance; National Health Interview Survey. $\mathrm{J}$ Gen Intern Med 34(8): 1494-502 DOI: $10.1007 / \mathrm{s} 11606-019-05002-\mathrm{w}$ (C) Society of General Internal Medicine 2019

\section{INTRODUCTION}

High out-of-pocket (OOP) spending for medical care is an increasingly critical issue for patients in the USA. ${ }^{1,2}$ High OOP spending can lead to asset depletion and medical debt, ${ }^{3}$ as well as distress and worry about household finances. ${ }^{3}$ Patients may delay or forgo needed medical care because of cost, ${ }^{3}$ jeopardizing benefits of treatment. Illness can also impact the ability to work and reduce productivity, limiting household income, and potentially reducing access to employer-sponsored health insurance in the working age population ages $18-64$ years.

Medical financial hardship is increasingly studied in newly diagnosed cancer patients and cancer survivors, ${ }^{3-7}$ more than $50 \%$ of cancer survivors report problems paying medical bills, financial distress, or delaying and/or forgoing medical care in the past year. ${ }^{8}$ In one of the few studies to address mortality outcomes associated with financial hardship, cancer survivors who filed for bankruptcy protection had greater risk of death than those who did not, even after considering the effects of sociodemographic factors, clinical characteristics (e.g., cancer type, stage of disease at diagnosis), and cancer treatment. ${ }^{9}$ Hypothesized mechanisms for the association between bankruptcy and increased mortality risk include limited access to necessary goods due to material resource constraints (e.g., food insecurity), stress and distress, and poor adherence to health care due to financial reasons. ${ }^{3}$

Within oncology, several conceptual frameworks have been proposed for studying medical financial hardship to inform its measurement and development of interventions to minimize its effects. ${ }^{3,}{ }^{10-14}$ de Souza and colleagues developed and validated a financial toxicity measure for use in patients receiving cancer treatment. ${ }^{10,11,15}$ Khera proposed a four-level financial toxicity grading criteria, ranging from lifestyle changes resulting from OOP expenses (grade 1) to stopping treatment or considering suicide because of OOP expenses (grade 4). ${ }^{12}$ In describing financial toxicity, Zafar and Abernethy highlighted OOP expenses and other components of objective financial burden as well as subjective financial 
Table 1 Sample Characteristics, 2015 to 2017 National Health Interview Survey

\begin{tabular}{|c|c|c|c|c|c|}
\hline & \multicolumn{4}{|c|}{ Age group } & \multirow[t]{3}{*}{$P$} \\
\hline & \multicolumn{2}{|c|}{ Age 18-64 years } & \multicolumn{2}{|c|}{ Age $65+$ years } & \\
\hline & No. & Weighted \% & No. & Weighted \% & \\
\hline Total & 68,828 & 100.0 & 24,614 & 100.0 & - \\
\hline Current age & & & & & - \\
\hline $18-34$ & 23,281 & 37.1 & - & - & \\
\hline $35-44$ & 14,011 & 20.5 & - & - & \\
\hline $45-54$ & 15,079 & 21.5 & - & - & \\
\hline $55-64$ & 16,457 & 20.9 & - & - & \\
\hline $65-74$ & - & - & 14,033 & 59.2 & \\
\hline $75+$ & _- & - & 10,581 & 40.8 & \\
\hline Sex & & & & & $<.0001$ \\
\hline Male & 31,870 & 49.1 & 10,288 & 44.6 & \\
\hline Female & 36,958 & 50.9 & 14,326 & 55.4 & \\
\hline Race/ethnicity & & & & & $<.0001$ \\
\hline Non-Hispanic white & 43,717 & 61.2 & 18,858 & 77.1 & \\
\hline Non-Hispanic black & 8385 & 12.5 & 2475 & 8.8 & \\
\hline Hispanic & 10,754 & 17.6 & 1887 & 8.2 & \\
\hline Asian and other & 5972 & 8.7 & 1394 & 5.9 & \\
\hline Current marital status & & & & & $<.0001$ \\
\hline Married/living as married & 30,832 & 52.1 & 10,482 & 55.9 & \\
\hline Other & 37,996 & 47.9 & 14,132 & 44.1 & \\
\hline Educational attainment & & & & & $<.0001$ \\
\hline$<$ High school graduate & 9738 & 14.4 & 4895 & 18.9 & \\
\hline High school graduate & 13,955 & 20.9 & 6355 & 25.7 & \\
\hline Some college or more & 45,135 & 64.7 & 13,364 & 55.3 & \\
\hline Family income as $\%$ of FPL & & & & & $<.0001$ \\
\hline$<200 \%$ & 22,630 & 28.8 & 7516 & 25.8 & \\
\hline $200-399 \%$ & 17,611 & 25.9 & 7210 & 29.0 & \\
\hline$>400 \%$ & 25,047 & 39.5 & 7333 & 34.4 & \\
\hline Missing & 3540 & 5.8 & 2555 & 10.9 & \\
\hline Current insurance status* & & & & & - \\
\hline $18-64$ years, private only & 46,485 & 69.1 & - & - & \\
\hline $18-64$ years, some public & 13,413 & 18.0 & - & - & \\
\hline 18-64 years, uninsured & 8930 & 12.9 & - & - & \\
\hline $65+$ years, Medicare + private & - & - & 11,243 & 47.1 & \\
\hline $65+$ years, Medicare + public & _- & _- & 3764 & 14.8 & \\
\hline $65+$ years, Medicare only & - & - & 8523 & 38.1 & \\
\hline Condition count ${ }^{\dagger}$ & & & & & $<.0001$ \\
\hline 0 & 32,924 & 49.8 & 2527 & 10.3 & \\
\hline 1 & 17,954 & 26.2 & 4482 & 18.0 & \\
\hline 2 & 9295 & 12.8 & 5810 & 23.8 & \\
\hline $3+$ & 8655 & 11.2 & 11,795 & 47.9 & \\
\hline Prescription drug in the past 12 months & & & & & $<.0001$ \\
\hline Yes & 40,959 & 57.6 & 21,015 & 85.6 & \\
\hline No & 27,869 & 42.4 & 3599 & 14.4 & \\
\hline Survey year & & & & & 0.1275 \\
\hline 2015 & 25,294 & 33.2 & 8378 & 32.3 & \\
\hline 2016 & 24,126 & 33.4 & 8902 & 33.3 & \\
\hline 2017 & 19,408 & 33.4 & 7334 & 34.4 & \\
\hline
\end{tabular}

$N=93,442$. Data from the 2015-2017 National Health Interview Survey. P values were derived from chi-square test. Italics type indicates statistical significance

FPL, federal poverty level; CI, confidence interval

*Individuals aged 65+ years with no insurance coverage, other insurance type, or missing were not shown in the current insurance status. Public insurance included Medicare, Medicaid, and/or other government/public coverage

the number of chronic conditions was defined as the sum of the following conditions that a respondent was ever told by a doctor or other health professional that s/he had arthritis, asthma, diabetes, emphysema, coronary heart disease, hypertension, stroke, angina pectoris, heart attack, high cholesterol, and cancer. Nonmelanoma skin cancer was not counted as a condition. Any cancer was measured as a single condition

$¥$ The medication prescribed status was measured by the yes/no question: During the past 12 months, were you prescribed medication by a doctor or other health professional?

distress. $^{14}$ Building on the health disparities literature, ${ }^{16}$ Tucker-Seeley and Yabroff proposed three domains of medical financial hardship: (1) material conditions that arise from increased OOP expenses and lower income (e.g., medical debt); (2) psychological responses (e.g., distress, worry); and (3) coping behaviors (e.g., delaying or forgoing care because of cost). ${ }^{3}$ The latter framework reflects a broad multidimensional conceptualization of medical financial hardship and the material, psychological, and behavioral domains are consistent with hypothesized mechanisms for increased mortality risk associated with bankruptcy. ${ }^{9}$ Further, this framework has been widely adopted within oncology. 3, 8, 17-19

Despite the risk of adverse health consequences of medical financial hardship, ${ }^{9}$ less is known about it in the general 


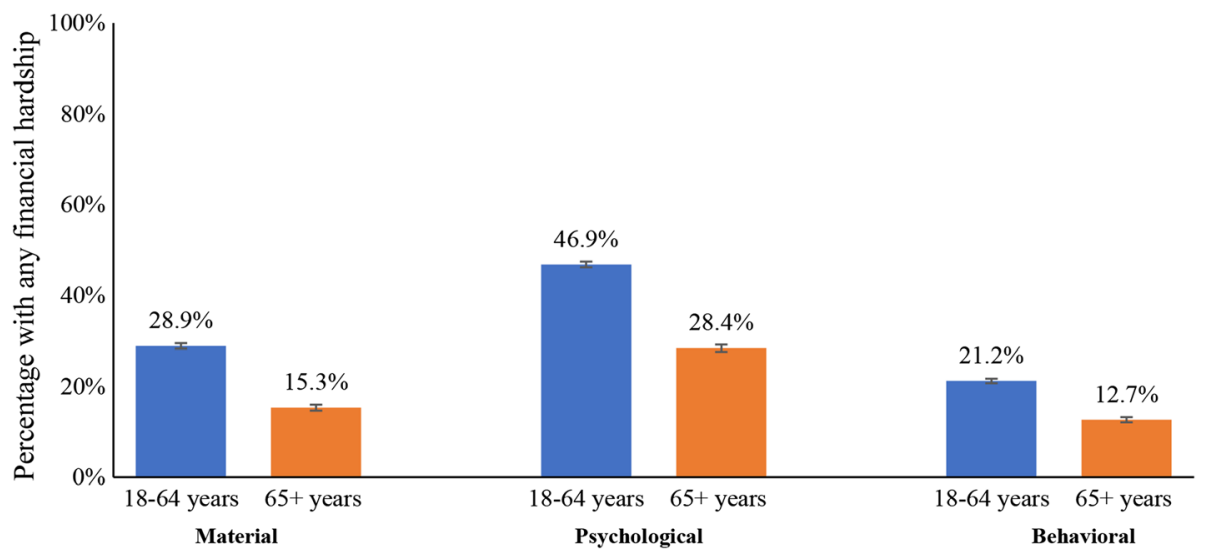

Figure 1 Any material, psychological, or behavioral medical financial hardship by age group. All $p<0.001$. Data from 2015 to 2017 National Health Interview Survey.

population, outside of oncology. Using the most recently available data, we address this research gap by assessing the prevalence of material, psychological and behavioral domains of financial hardship and correlates of financial hardship in a nationally representative sample of adults in the USA.

\section{METHODS}

We identified adults aged $\geq 18$ years from the 2015-2017 National Health Interview Survey (NHIS), an annual household survey of the civilian non-institutionalized population. ${ }^{20}$ Selected sociodemographic characteristics included age, sex, race/ethnicity, marital status, educational attainment, and family income as a percentage of federal poverty level (FPL). Health conditions were identified from responses to the question, "Has a doctor or other health professional ever told you that you have.. arthritis, asthma, cancer, diabetes, emphysema, coronary heart disease, hypertension, stroke, angina pectoris, and heart attack?" The number of conditions was summarized as a categorical variable $(0,1,2,3+)$. Health insurance coverage was measured separately for adults aged 18-64 years (any private, public only, uninsured) and $\geq 65$ years (Medicare and private, Medicare and public, Medicare only). Public coverage includes Medicare (for adults aged 18-64 years), Medicaid, and other government/public coverage. We also measured receipt of prescription drugs in the past year based on the question, "During the past 12 months, were you prescribed medication by a doctor or other health professional?"

Material hardship was measured as problems paying medical bills and/or paying off medical bills over time; psychological hardship, as worry about paying costs of serious illness and/or normal health care; and behavioral hardship, as delaying and/or forgoing care due to worry about cost and/or being unable to afford needed care (Supplemental Table 1 contains exact wording of questions). We created a dichotomous summary measure for each hardship domain and generated an intensity measure of zero, one, and two or three domain(s) of hardship based on the three summary measures. We used the NHIS sample weights to generate national estimates of any medical financial hardship for the US population in millions. All analyses were stratified by age group $(18-64$ years $(N=68,828)$ and $\geq 65$ years $(N=24,614))$ to reflect differences in age eligibility for Medicare. Descriptive characteristics were compared by chi-square statistics. We assessed the association between sociodemographic characteristics and material, psychological, or behavioral hardship and report unadjusted percentages for the effects of demographic factors. We used generalized ordinal logistic regression models to generate adjusted predicted margins for hardship intensity (none, one, or multiple domains). All analyses accounted for the complex NHIS design and nonresponse using SAS 9.4 and STATA/IC 14.1. Statistical tests were two-sided, and significance was defined as $p<0.05$.

\section{RESULTS}

Sample characteristics stratified by age group (18-64 years and $\geq$ 65 years) are listed in Table 1. In both age groups, most adults were non-Hispanic white and at least one-third had family incomes > $400 \%$ of the FPL. Nearly $70 \%$ of adults aged $18-64$ years reported private insurance coverage and nearly $50 \%$ of adults $\geq 65$ years reported Medicare and private insurance coverage. Distributions of health conditions were very different by age group - substantially more adults aged $\geq 65$ years reported at least three health conditions than adults aged $18-64(47.9 \%$ vs. $11.2 \%)$. Conversely, fewer adults aged $\geq 65$ years reported not having any health conditions compared to those aged 18-64 (10.3\% vs. $49.8 \%$ ). Receipt of any prescription drugs in the past 12 months was also much higher in adults aged $\geq 65$ years than those aged 18 64 years $(85.6 \%$ vs. $57.6 \%)$.

Overall, $56.0 \%$ of adults reported any medical financial hardship, representing 137.1 million adults (95\% CI 132.7141.5) in the USA (Supplemental Table 2). Compared with adults aged $\geq 65$ years, adults aged 18-64 years reported higher material ( $28.9 \%$ vs. $15.3 \%)$, psychological ( $46.9 \%$ vs. $28.4 \%$ ), or behavioral (21.2\% vs. $12.7 \%$ ) financial hardship (all $p<.001$, Fig. 1). In both age groups, material, behavioral, and psychological financial hardship varied significantly by 
health insurance coverage in both unadjusted (Supplemental Tables 3-5) and adjusted analyses (Fig. 2). In the younger age group, all domains of hardship were highest for the uninsured compared to those with any private insurance or those with public insurance only. Among those aged $\geq 65$ years, all domains of hardship were highest among those with Medicare only and lower for those with Medicare and private or public insurance, although differences were less pronounced than in those aged 18-64 years. Receipt of prescription drugs in the past year was associated with higher material, psychological, and behavioral hardship in both age groups in adjusted analyses (all $p<.001$, Fig. 3).

Factors associated with the intensity of medical financial hardship in the younger age group are described (Table 2).
More than half reported at least one domain of hardship. Adults with less educational attainment and more health conditions were more likely to report great intensity of hardship. Women were more likely to report multiple domains of hardship than men. The uninsured were more likely to report multiple domains of hardship (52.8\%), compared to those with some public $(26.5 \%)$ and private insurance $(23.2 \%)(p<.001)$.

In the older age group, more than one-third reported at least one domain of medical financial hardship (Table 3). Similar to findings in the younger population, older adults with less educational attainment and more health conditions were more likely to report greater intensity of hardship, as were women. Individuals with Medicare only were most likely to report hardship in multiple domains $(17.1 \%)$ compared to those with
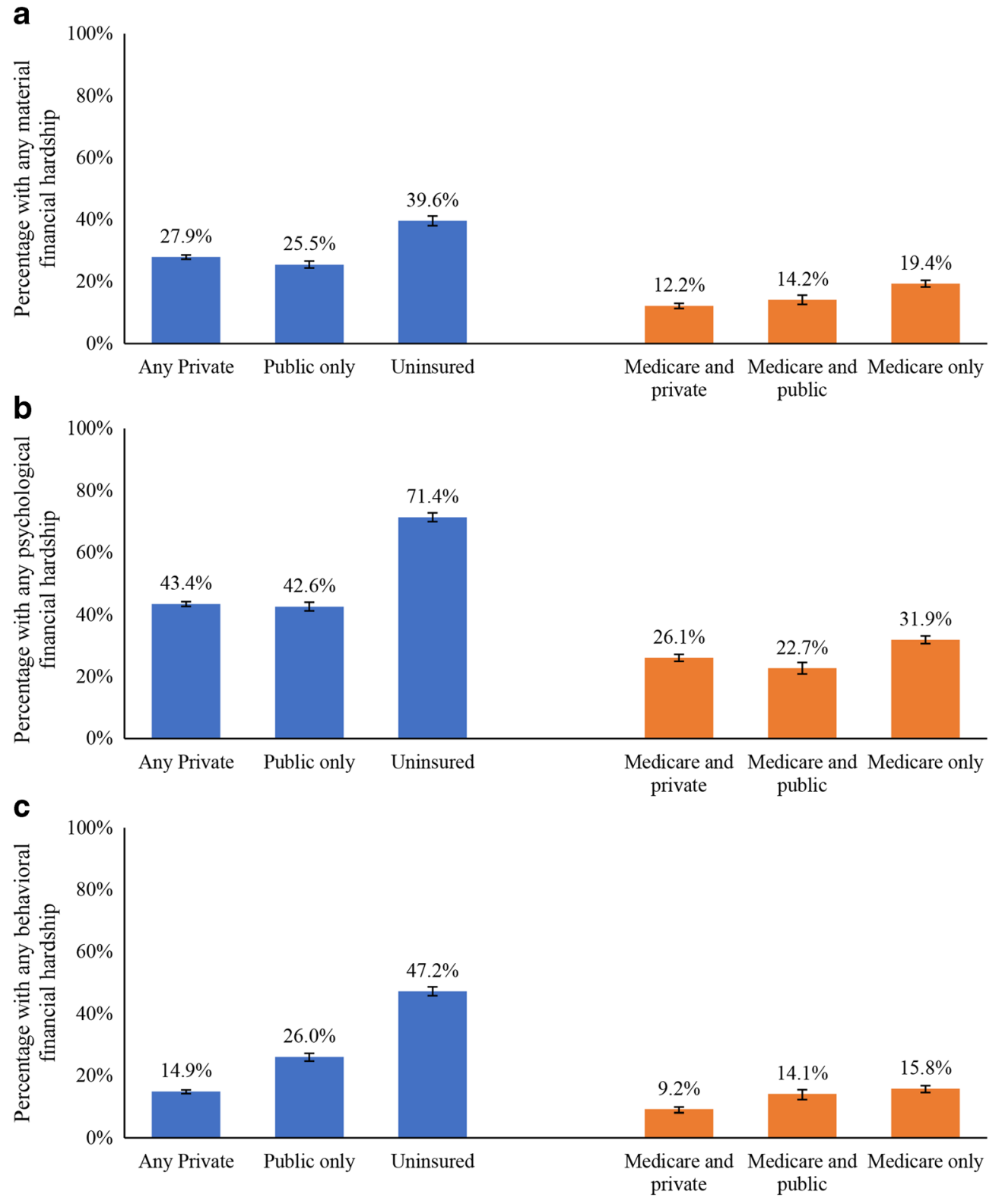

Figure 2 Any medical financial hardship by age group by age and type of health insurance coverage. a Material hardship. b Psychological hardship. c Behavioral hardship. Multivariable logistic regression models controlled for the effects of age, sex, race/ethnicity, marital status, educational attainment, and number of health conditions and results are presented as adjusted predicted margins. All $p<0.001$. Data from 2015 to 2017 National Health Interview Survey. 


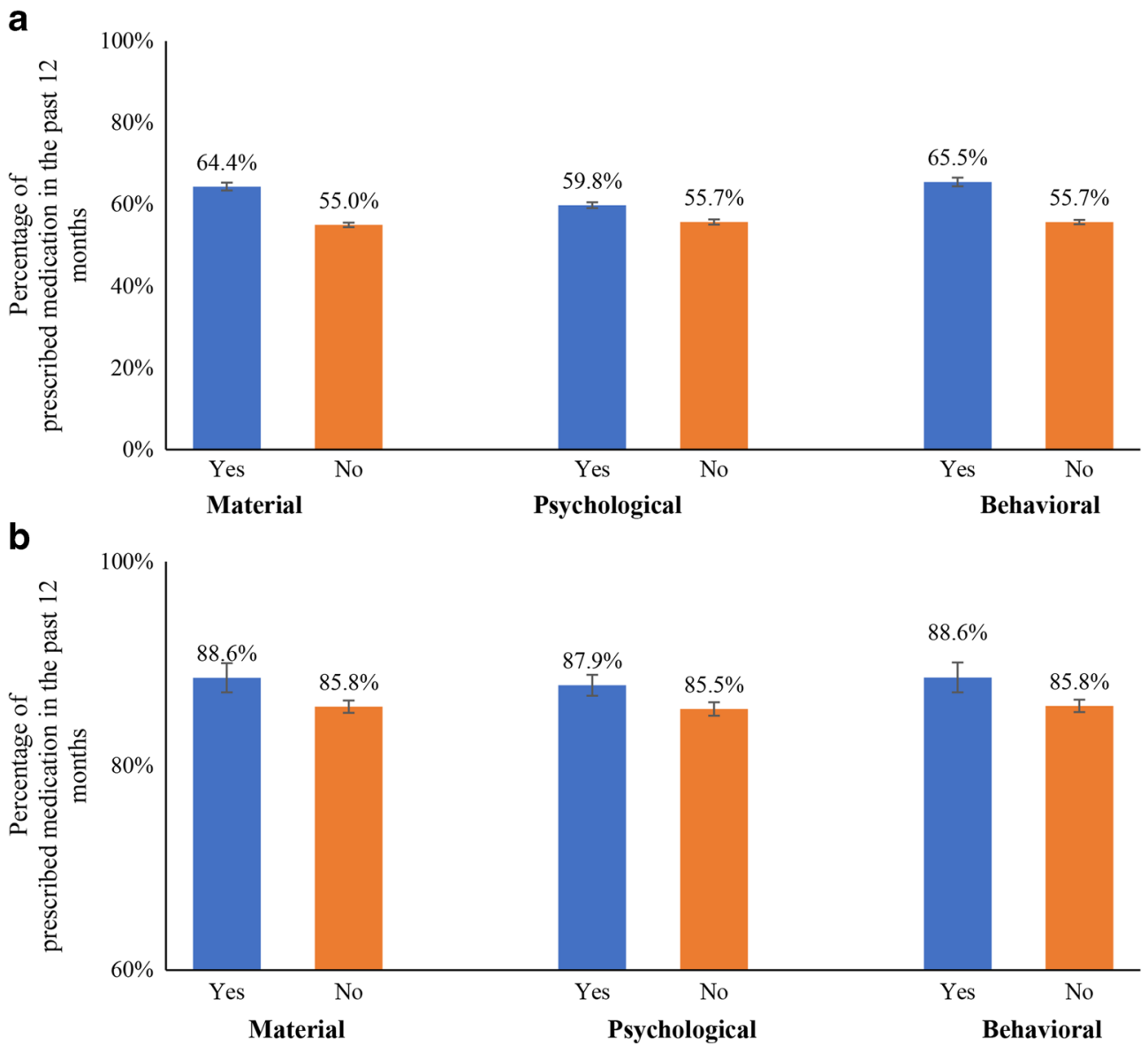

Figure 3 Medical financial hardship and medication prescribed status in the past 12 months. a Aged 18-64 years. b Aged 65+ years. The medication prescribed status was measured by the yes/no question: During the past 12 months, were you prescribed medication by a doctor or other health professional? Age, sex, race/ethnicity, marital status, educational attainment, insurance status, condition count, and survey year were adjusted in the regression. All $p<0.001$. Data from 2015 to 2017 National Health Interview Survey.

Medicare and public (12.1\%) or Medicare and private coverage $(10.1 \%)(p<.001)$.

\section{DISCUSSION}

In this study, we used the most recent national data to explore material, psychological, and behavioral domains of medical financial hardship in the USA and found that 137.1 million adults reported any medical financial hardship in the past year. Among adults aged 18-64 years, more than half reported at least one and about one-fourth reported at least two domains of financial hardship. Hardship and its relative intensity were significantly lower in the older group, despite higher prevalence of multiple chronic conditions and lower household income ${ }^{21}$ illustrating the protective effects of Medicare coverage. Even so, more than one-third of those aged $\geq 65$ years reported at least one domain of hardship. With recent trends towards increasing prevalence of multiple chronic conditions ${ }^{22}$ higher patient cost-sharing, ${ }^{23}$ and increasing costs of health care ${ }^{24}$, the risks of financial hardship will likely increase in the future. Thus, unless addressed, medical financial hardship may become an increasingly common consequence of illness in adults of all ages. Research addressing aspects of medical financial hardship is increasing in other countries, ${ }^{25-}$ 28 and in older studies, adults in the USA have higher OOP spending on health care than in European countries. ${ }^{27,}{ }^{28}$ Our findings are not directly comparable to those in other countries because of important differences in measures of financial hardship and health system features, as well as study populations. Understanding the role of health care system features in development of medical financial hardship and adverse health outcomes will be important for future research.

We found striking differences in financial hardship by type of health insurance coverage - more than three-fourths of the uninsured aged 18-64 years reported any hardship and more than half reported multiple domains of hardship. In contrast, closer to one-fourth of those aged 18-64 years with private insurance coverage reported multiple domains of hardship. Because the uninsured have historically experienced worse access to care and poorer health outcomes, ${ }^{29}$ addressing medical financial hardship will be especially important for this group, to minimize the risk of widening health disparities. In addition, with more than $40 \%$ of working age adults aged 18 64 years receiving coverage through high-deductible health insurance plans ${ }^{30,} 31$ and greater cost-sharing among the 
Table 2 Association Between Patient Factors and Intensity of Medical Financial Hardship, Aged 18-64 years, 2015 to 2017 National Health Interview Survey

\begin{tabular}{|c|c|c|c|c|c|c|c|}
\hline & \multicolumn{2}{|c|}{ No financial hardship } & \multicolumn{2}{|l|}{ One domain } & \multicolumn{2}{|c|}{ Two or three domains } & \multirow[t]{2}{*}{$P$ value } \\
\hline & Weighted \% & $95 \% \mathrm{CI}$ & Weighted \% & $95 \% \mathrm{CI}$ & Weighted \% & $95 \% \mathrm{CI}$ & \\
\hline \multicolumn{7}{|l|}{ Current age } & $<0.0001$ \\
\hline $18-34$ & 41.7 & $(40.7,42.6)$ & 30.7 & $(29.8,31.6)$ & 27.6 & $(26.7,28.5)$ & \\
\hline $35-44$ & 35.5 & $(34.4,36.6)$ & 33.8 & $(32.7,34.8)$ & 30.7 & $(29.8,31.7)$ & \\
\hline $45-54$ & 37.4 & $(36.3,38.4)$ & 33.6 & $(32.6,34.6)$ & 29.0 & $(28.0,30.0)$ & \\
\hline $55-64$ & 43.6 & $(42.5,44.7)$ & 32.8 & $(31.7,33.8)$ & 23.7 & $(22.8,24.6)$ & \\
\hline \multicolumn{7}{|l|}{ Sex } & $<0.0001$ \\
\hline Male & 43.6 & $(42.8,44.4)$ & 32.4 & $(31.7,33.1)$ & 24.0 & $(23.3,24.6)$ & \\
\hline Female & 36.3 & $(35.6,37.0)$ & 32.5 & $(31.8,33.1)$ & 31.2 & $(30.5,31.9)$ & \\
\hline \multicolumn{7}{|l|}{ Race/ethnicity. } & $<0.0001$ \\
\hline Non-Hispanic white & 40.7 & $(40.1,41.4)$ & 31.4 & $(30.8,32.0)$ & 27.9 & $(27.3,28.5)$ & \\
\hline Other & 38.5 & $(37.5,39.5)$ & 34.3 & $(33.5,35.1)$ & 27.2 & $(26.4,28.0)$ & \\
\hline \multicolumn{7}{|l|}{ Current marital status } & $<0.0001$ \\
\hline Married/living as married & 40.6 & $(39.9,41.3)$ & 32.7 & $(32.1,33.4)$ & 26.7 & $(26.0,27.4)$ & \\
\hline Other & 39.1 & $(38.3,39.8)$ & 32.3 & $(31.6,33.0)$ & 28.7 & $(28.0,29.3)$ & \\
\hline \multicolumn{7}{|l|}{ Educational attainment } & $<0.0001$ \\
\hline$<$ High school graduate & 34.5 & $(33.2,35.9)$ & 33.5 & $(32.1,34.9)$ & 32.0 & $(30.7,33.3)$ & \\
\hline High school graduate & 36.4 & $(35.3,37.6)$ & 35.0 & $(33.9,36.1)$ & 28.6 & $(27.6,29.6)$ & \\
\hline Some college or more & 42.0 & $(41.3,42.7)$ & 31.8 & $(31.2,32.4)$ & 26.2 & $(25.6,26.8)$ & \\
\hline \multicolumn{7}{|l|}{ Current insurance status* } & $<0.0001$ \\
\hline $18-64$ years, private only & 43.6 & $(42.9,44.4)$ & 33.2 & $(32.6,33.8)$ & 23.2 & $(22.5,23.8)$ & \\
\hline 18-64 years, some public & 40.9 & $(39.5,42.3)$ & 32.5 & $(31.2,33.8)$ & 26.5 & $(25.4,27.6)$ & \\
\hline 18-64 years, uninsured & 17.9 & $(16.8,19.1)$ & 29.3 & $(28.0,30.6)$ & 52.8 & $(51.1,54.4)$ & \\
\hline \multicolumn{7}{|l|}{ Condition count ${ }^{\dagger}$} & $<0.0001$ \\
\hline 0 & 46.0 & $(45.2,46.8)$ & 33.0 & $(32.3,33.7)$ & 21.0 & $(20.3,21.6)$ & \\
\hline 1 & 37.9 & $(36.9,38.9)$ & 33.1 & $(32.1,34.1)$ & 29.0 & $(28.1,29.9)$ & \\
\hline 2 & 32.7 & $(31.4,33.9)$ & 31.3 & $(30.0,32.6)$ & 36.0 & $(34.7,37.3)$ & \\
\hline $3+$ & 26.3 & $(25.0,27.6)$ & 28.0 & $(26.5,29.5)$ & 45.8 & $(44.1,47.4)$ & \\
\hline \multicolumn{7}{|l|}{ Survey year } & 0.3779 \\
\hline 2015 & 39.6 & $(38.7,40.5)$ & 32.7 & $(31.8,33.5)$ & 27.7 & $(27.0,28.4)$ & \\
\hline 2016 & 40.6 & $(39.7,41.5)$ & 32.0 & $(31.2,32.8)$ & 27.4 & $(26.6,28.3)$ & \\
\hline 2017 & 39.4 & $(38.4,40.4)$ & 32.8 & $(32.0,33.7)$ & 27.8 & $(26.8,28.7)$ & \\
\hline
\end{tabular}

$N=68,828$. Data from the 2015-2017 National Health Interview Survey. The three domains included material, psychological, and behavioral financial hardship. Age, sex, racelethnicity, marital status, educational attainment, insurance status, condition count, and survey year were adjusted in the regression. Italics type indicates statistical significance

FPL, federal poverty level; CI, confidence interval

*Public insurance included Medicare, Medicaid, and/or other government/public coverage

insured, ${ }^{32}$ health insurance coverage alone may be insufficient to fully protect the privately insured from medical financial hardship.

We also found that receipt of prescription drugs in the past year was associated with all domains of financial hardship, even after controlling for the effects of health conditions and sociodemographic factors. Others have shown that high OOP spending on prescription drugs plays an important role in financial hardship, ${ }^{33}$ even for those with private health insurance coverage. Increasingly, drugs for conditions such as cancer, rheumatoid arthritis, and multiple sclerosis have annual list prices of $>\$ 100,000$. With coinsurance of $\geq 20 \%$ for specialty drugs, ${ }^{23}$ patients can face $\geq \$ 20,000$ in OOP costs annually, which also has implications for health outcomes. High OOP costs are strongly associated with cost-related medication non-adherence, ${ }^{33,} 34$ and non-adherence is associated with greater risk of emergency room visits, ${ }^{35}$ preventable hospitalizations, ${ }^{36}$ and death. ${ }^{36}$ Other components of health care, such as advanced imaging and novel surgical techniques, may also play a role in rising patient OOP costs. Evaluation of the role of prescription drugs and other components of health care in financial hardship and related effects on health outcomes will be an important area for additional research using longitudinal study designs.

Lower educational attainment was associated with greater medical financial hardship intensity in both age groups. These findings are consistent with other studies evaluating financial hardship ${ }^{37}$ and access to care. ${ }^{38}$ In addition to being a measure of socioeconomic position, educational attainment may reflect health literacy and health insurance literacy, factors independently associated with access to care. ${ }^{39,}{ }^{40}$ With complex and continuously changing health insurance system(s), patient health insurance literacy is increasingly receiving attention in the USA, ${ }^{41-43}$ especially because it is potentially modifiable by intervention. ${ }^{43-46}$

In recognition of adverse health consequences of financial hardship, a number of patient-level intervention strategies have been developed to reduce its impact, including educational programs aimed at improving health insurance literacy, screening tools, financial navigation linking patients to community resources. ${ }^{47}$ Other efforts have focused on enhancing patient-provider discussions about expected costs and benefits of care. ${ }^{48,}{ }^{49}$ Insurer-level strategies, such as the value-based insurance design (VBID), which focus on providing high- 
Table 3 Association Between Patient Factors and Intensity of Medical Financial Hardship, Aged 65+ years, 2015 to 2017 National Health Interview Survey

\begin{tabular}{|c|c|c|c|c|c|c|c|}
\hline & \multicolumn{2}{|c|}{ No financial hardship } & \multicolumn{2}{|l|}{ One domain } & \multicolumn{2}{|c|}{ Two or three domains } & \multirow[t]{2}{*}{$P$ value } \\
\hline & Weighted \% & $95 \% \mathrm{CI}$ & Weighted \% & $95 \% \mathrm{CI}$ & Weighted \% & $95 \% \mathrm{CI}$ & \\
\hline Current age & & & & & & & $<0.0001$ \\
\hline $65-74$ & 56.3 & $(55.2,57.3)$ & 27.7 & $(26.6,28.7)$ & 16.1 & $(15.2,17.0)$ & \\
\hline $75+$ & 68.1 & $(66.9,69.4)$ & 22.5 & $(21.4,23.5)$ & 9.4 & $(8.6,10.1)$ & \\
\hline Sex & & & & & & & $<0.0001$ \\
\hline Male & 63.8 & $(62.6,65.0)$ & 24.1 & $(23.0,25.2)$ & 12.2 & $(11.3,13.0)$ & \\
\hline Female & 59.4 & $(58.3,60.5)$ & 26.8 & $(25.8,27.8)$ & 13.8 & $(13.0,14.7)$ & \\
\hline Race/ethnicity & & & & & & & $<0.0001$ \\
\hline Non-Hispanic white & 63.1 & $(62.2,64.1)$ & 24.6 & $(23.7,25.4)$ & 12.3 & $(11.6,13.0)$ & \\
\hline Other & 55.0 & $(53.3,56.8)$ & 29.4 & $(27.8,31.0)$ & 15.6 & $(14.3,16.8)$ & \\
\hline Current marital status & & & & & & & $<0.0001$ \\
\hline Married/living as married & 63.6 & $(62.4,64.8)$ & 24.8 & $(23.8,25.9)$ & 11.6 & $(10.8,12.4)$ & \\
\hline Other & 58.5 & $(57.4,59.6)$ & 26.5 & $(25.5,27.6)$ & 15.0 & $(14.1,15.8)$ & \\
\hline Educational attainment & & & & & & & $<0.0001$ \\
\hline$<$ High school graduate & 53.0 & $(51.0,55.0)$ & 29.4 & $(27.6,31.3)$ & 17.6 & $(16.0,19.3)$ & \\
\hline High school graduate & 60.1 & $(58.6,61.7)$ & 26.8 & $(25.4,28.3)$ & 13.0 & $(11.9,14.1)$ & \\
\hline Some college or more & 64.7 & $(63.6,65.8)$ & 23.8 & $(22.8,24.8)$ & 11.5 & $(10.8,12.2)$ & \\
\hline Current insurance status* & & & & & & & $<0.0001$ \\
\hline $65+$ years, Medicare + private & 64.8 & $(63.6,66.0)$ & 25.1 & $(24.0,26.2)$ & 10.1 & $(9.3,10.9)$ & \\
\hline $65+$ years, Medicare + public & 63.6 & $(61.4,65.8)$ & 24.3 & $(22.4,26.2)$ & 12.1 & $(10.7,13.5)$ & \\
\hline $65+$ years, Medicare only & 56.1 & $(54.9,57.4)$ & 26.8 & $(25.6,28.0)$ & 17.1 & $(16.0,18.1)$ & \\
\hline Condition count & & & & & & & $<0.0001$ \\
\hline 0 & 71.5 & $(69.2,73.8)$ & 20.9 & $(18.7,23.1)$ & 7.6 & $(6.2,9.0)$ & \\
\hline 1 & 66.3 & $(64.6,68.0)$ & 24.3 & $(22.7,25.9)$ & 9.4 & $(8.1,10.7)$ & \\
\hline 2 & 63.0 & $(61.3,64.7)$ & 25.9 & $(24.4,27.5)$ & 11.0 & $(10.0,12.1)$ & \\
\hline $3+$ & 56.6 & $(55.4,57.7)$ & 26.8 & $(25.7,27.8)$ & 16.7 & $(15.7,17.6)$ & \\
\hline Survey year & & & & & & & 0.1418 \\
\hline 2015 & 62.3 & $(60.8,63.7)$ & 25.0 & $(23.7,26.3)$ & 12.7 & $(11.7,13.8)$ & \\
\hline 2016 & 61.9 & $(60.4,63.3)$ & 25.4 & $(24.1,26.6)$ & 12.7 & $(11.8,13.6)$ & \\
\hline 2017 & 59.9 & $(58.5,61.3)$ & 26.3 & $(25.1,27.6)$ & 13.8 & $(12.8,14.8)$ & \\
\hline
\end{tabular}

$N=24,614$. Data from the 2015-2017 National Health Interview Survey. The three domains included material, psychological, and behavioral financial hardship. Age, sex, racelethnicity, marital status, educational attainment, insurance status, condition count, and survey year were adjusted in the regression. Italics type indicates statistical significance

FPL, federal poverty level; $C I$, confidence interval

*Individuals aged 65+ years with no insurance coverage, other insurance type, or missing were not shown in the current insurance status. Public insurance included Medicaid,and/or other government/public coverage

quality rather than high-volume care, are associated with reduced patient OOP costs in some settings. ${ }^{50}$ To date, however, VBID for prescription drugs has generally focused on specific drug classes or generic substitution and rarely addresses OOP costs for specialty drugs or for drugs without generic substitutes. Little research has reported effects of value-based episodes of care or bundled payment models on patient OOP costs or financial hardship. Development and evaluation of interventions to minimize financial hardship and adverse health outcomes at the patient, provider, and insurer levels are ongoing.

State-level Medicaid eligibility expansions as part of the implementation of the Affordable Care Act are associated with increased health insurance coverage, ${ }^{51,52}$ access to care, ${ }^{52,53}$ and reduced financial strain ${ }^{53}$ and worry about paying bills ${ }^{52}$ in low-income adult populations $\leq 64$ years, but not all states have expanded eligibility for Medicaid coverage. Even in states that did expand Medicaid eligibility, some low-income individuals remain uninsured and many of the insured face challenges with health care affordability. Other state-level policies, such as those addressing price transparency, ${ }^{54,55}$ surprise medical bills, ${ }^{56}$ generic drug substitution by pharmacists, ${ }^{55}$ and requirements for some employers to offer employees paid sick leave ${ }^{57}$ could reduce the risk of medical financial hardship, but to date, little research has been conducted to evaluate their impact. Evaluating the effects of state and federal health policies on patient OOP and financial hardship will be important for future research.

Despite the strengths of the most recent population-based nationally representative data to explore multiple domains of financial hardship, this study is subject to bias introduced by self-reported measures. Medical record data were not available from the NHIS and the NHIS did not include detailed questions about the underlying cause of different aspects of medical financial hardship. Further, questions were not specific about the health effects resulting directly from financial hardship, including health-related quality of life. Data were crosssectional and we could not evaluate long-term health implications of hardship, nor do our findings provide specific details for intervention development. Nonetheless, the fact that many Americans are having trouble paying medical bills, experiencing significant distress, and delaying or forgoing care due to cost is important information for patients, health care providers, health plans, and policy makers. Improving 
understanding and measurement of medical financial hardship and developing and evaluating effective interventions to reduce its risk will be important for future research.

In summary, medical financial hardship is common among adults in the USA, with nearly 140 million adults reporting hardship in the past year. Among those aged 18-64 years, more than half report problems with medical bills or medical debt; stress or worry; or forgoing or delaying health care due to cost. The highest prevalence and greatest intensity of medical financial hardship are among the uninsured. With increasing prevalence of multiple chronic conditions, ${ }^{22}$ higher patient cost-sharing, ${ }^{23}$ and higher costs of health care, ${ }^{24}$ the risk of hardship will likely increase in the future. Thus, development and evaluation of the comparative effectiveness and costeffectiveness of strategies to minimize medical financial hardship will be important.

Corresponding Author: K. Robin Yabroff, Ph.D; Surveillance and Health Services Research Program, American Cancer Society, Atlanta, GA, USA (e-mail: Robin.yabroff@cancer.org).

\section{Compliance with Ethical Standards:}

Conflict of Interest: The authors declare that they do not have a conflict of interest.

\section{REFERENCES}

1. Ubel PA, Abernethy AP, Zafar SY. Full disclosure-out-of-pocket costs as side effects. New Engl J Med 2013;369(16):1484-1486.

2. Cohen RA, Kirzinger WK. Financial burden of medical care: a family perspective. NCHS Data Brief 2014. Accessed January 15, 2019.

3. Altice CK, Banegas MP, Tucker-Seeley RD, Yabroff KR. Financial Hardships Experienced by Cancer Survivors: A Systematic Review. J Natl Cancer Inst. 2017;109(2).

4. Zafar SY, McNeil RB, Thomas CM, Lathan CS, Ayanian JZ, Provenzale D. Population-based assessment of cancer survivors' financial burden and quality of life: a prospective cohort study. J Oncol Pract 2015;11(2):145-150.

5. Nipp RD, Zullig LL, Samsa G, et al. Identifying cancer patients who alter care or lifestyle due to treatment-related financial distress. Psychooncology. 2016;25(6):719-725.

6. Carrera PM, Kantarjian HM, Blinder vS. The financial burden and distress of patients with cancer: Understanding and stepping-up action on the financial toxicity of cancer treatment. CA Cancer $\mathrm{J}$ Clin 2018;68(2):153-165.

7. Gordon LG, Merollini KMD, Lowe A, Chan RJ. A Systematic Review of Financial Toxicity Among Cancer Survivors: We Can't Pay the Co-Pay. Patient. 2017;10(3):295-309.

8. Zheng ZHX, Guy GP Jr, Li C, Banegas MP, Ekwueme DU, Davidoff AJ, Jemal A, Yabroff KR. . Medical financial hardship among cancer survivors in the US. Cancer. 2018;in press.

9. Ramsey SD, Bansal A, Fedorenko CR, et al. Financial Insolvency as a Risk Factor for Early Mortality Among Patients With Cancer. J Clin Oncol: Off J Am Soc Clin Oncol 2016;34(9):980-986.

10. de Souza JA, Yap BJ, Hubocky FJ, et al. The development of a financial toxicity patient-reported outcome in cancer: The COST measure. Cancer. 2014; 120(20):3245-3253.

11. de Souza JA, Yap BJ, Wroblewski K, et al. Measuring financial toxicity as a clinically relevant patient-reported outcome: The validation of the COmprehensive Score for financial Toxicity (COST). Cancer. 2017;123(3):476-484

12. Khera N. Reporting and grading financial toxicity. J Clin Oncol: Off $\mathrm{J}$ Am Soc Clin Oncol. 2014;32(29):3337-3338.
13. Zafar SY, Abernethy AP. Financial toxicity, Part II: how can we help with the burden of treatment-related costs? Oncology (Williston Park, NY). 2013;27(4):253-254, 256.

14. Zafar SY, Abernethy AP. Financial toxicity, Part I: a new name for a growing problem. Oncology (Williston Park, NY). 2013;27(2):80-81, 149.

15. de Souza JA, Kung S, O'Connor J, Yap BJ. Determinants of PatientCentered Financial Stress in Patients With Locally Advanced Head and Neck Cancer. J Oncol Pract. 2017;13(4):e310-e318.

16. Skalicka V, van Lenthe F, Bambra C, Krokstad S, Mackenbach J. Material, psychosocial, behavioural and biomedical factors in the explanation of relative socio-economic inequalities in mortality: evidence from the HUNT study. Int J Epidemiol. 2009;38(5):1272-1284.

17. Yabroff KR, Dowling EC, Guy GP Jr., et al. Financial Hardship Associated With Cancer in the United States: Findings From a Population-Based Sample of Adult Cancer Survivors. J Clin Oncol: Off J Am Soc Clin Oncol. 2016;34(3):259-267.

18. Banegas MP, Guy GP Jr., de Moor JS, et al. For Working-Age Cancer Survivors, Medical Debt And Bankruptcy Create Financial Hardships. Health Aff (Project Hope). 2016;35(1):54-61.

19. Huang IC, Bhakta N, Brinkman TM, et al. Determinants and Consequences of Financial Hardship Among Adult Survivors of Childhood Cancer: A Report From the St. Jude Lifetime Cohort Study. J Natl Cancer Inst. 2018.

20. National Center for Health Statistics. National Health Interview Survey. https://www.cdc.gov/nchs/nhis/index.htm. Accessed January 15, 2019.

21. Guzman GG. American Community Survey Briefs. Household Income: 2016. https://www.census.gov/content/dam/Census/library/publications/2017/acs/acsbr16-02.pdf. 2017. Accessed January 15, 2019.

22. Gerteis J, Izrael D, Deitz D, LeRoy L, Ricciardi R, Miller T, Basu J. Multiple chronic conditions chartbook. https://www.ahrq.gov/sites/default/files/wysiwyg/professionals/prevention-chronic-care/decision/ mcc/mccchartbook.pdf. 2014. Accessed January 15, 2019.

23. Claxton G, Levitt L, Long $\mathbf{M}$. Payments for cost-sharing increasing rapidly over time. https://www.healthsystemtracker.org/brief/payments-for-cost-sharing-increasing-rapidly-over-time/. 2016. Accessed January 15, 2019.

24. Hartman M, Martin AB, Espinosa N, Catlin A, The National Health Expenditure Accounts T. National Health Care Spending In 2016: Spending And Enrollment Growth Slow After Initial Coverage Expansions. Health Aff (Project Hope). 2018;37(1):150-160.

25. Gordon LG, Beesley VL, Mihala G, Koczwara B, Lynch BM. Reduced employment and financial hardship among middle-aged individuals with colorectal cancer. Eur J Cancer Care. 2017;26(5).

26. Hanly P, Maguire R, Ceilleachair AO, Sharp L. Financial hardship associated with colorectal cancer survivorship: The role of asset depletion and debt accumulation. Psycho-oncology. 2018;27(9):2165-2171.

27. Schoen C, Osborn R, Doty MM, Bishop M, Peugh J, Murukutla N Toward higher-performance health systems: adults' health care experiences in seven countries, 2007. Health Aff (Project Hope). 2007;26(6):w717-734.

28. Schoen C, Osborn R, Squires D, Doty MM. Access, affordability, and insurance complexity are often worse in the United States compared to ten other countries. Health Aff (Project Hope). 2013;32(12):2205-2215.

29. Institute of Medicine. Access to Healthcare in America. In: Millman M, ed. Washington, DC: National Academy Press; 1993.

30. Cohen RA, Zammitti EP. High-deductible Health Plans and Financial Barriers to Medical Care: Early Release of Estimates From the National Health Interview Survey, 2016. https://www.cdc.gov/nchs/data/nhis/ earlyrelease/ERHDHP_Access_0617.pdf. Accessed January 15, 2019.

31. Cohen R, Zammitti E. High-deductible health plan enrollment among adults aged 18-64 with employment-based insurance coverage. NCHS Data Brief, no 317. Hyattsville, MD: National Center for Health Statistics. 2018.

32. Henry $\mathbf{J}$ Kaiser Family Foundation. Payments for Cost Sharing Increasing Rapidly Over Time. 2017; https://www.kff.org/health-costs/issuebrief/payments-for-cost-sharing-increasing-rapidly-over-time/. Accessed January 15, 2019.

33. Briesacher BA, Gurwitz JH, Soumerai SB. Patients at-risk for costrelated medication nonadherence: a review of the literature. J Gen Intern Med. 2007;22(6):864-871.

34. Osterberg L, Blaschke T. Adherence to medication. New Engl J Med. 2005;353(5):487-497.

35. Blanchard J, Madden JM, Ross-Degnan D, Gresenz CR, Soumerai SB The relationship between emergency department use and cost-related 
medication nonadherence among Medicare beneficiaries. Ann Emerg Med. 2013;62(5):475-485.

36. Heisler M, Choi H, Rosen AB, et al. Hospitalizations and deaths among adults with cardiovascular disease who underuse medications because of cost: a longitudinal analysis. Med Care. 2010;48(2):87-94.

37. Yabroff KR, Zhao J, Zheng Z, Rai A, Han X. Medical Financial Hardship among Cancer Survivors in the United States: What Do We Know? What Do We Need to Know? Cancer epidemiology, biomarkers \& prevention : a publication of the American Association for Cancer Research, cosponsored by the American Society of Preventive Oncology: 2018.

38. Mandelblatt JS, Yabroff KR, Kerner JF. Equitable access to cancer services: A review of barriers to quality care. Cancer. 1999;86(11):23782390 .

39. Paez KA., Mallery, CJ. A little knowledge is a risky thing: Wide gap in what people think they know about health insurance and what they actually know. American Institutes for Research Issue Brief. http://www. air.org/resource/little-knowledge-risky-thing-wide-gap-what-peoplethink-they-know-about-health-insurance. 2014. Accessed January 15, 2019.

40. Tipirneni R PM, Kullgren JT, Kieffer EC, Goold SD, Scherer AM. Association Between Health Insurance Literacy and Avoidance of Health Care Services Owing to Cost. JAMA Netw Open. 2018; 1(7).

41. Norton M HL, Brodie M. Assessing Americans' Familiarity With Health Insurance Terms and Concepts. https://www.kfforg/health-reform/pollfinding/assessing-americans-familiarity-with-health-insurance-termsand-concepts/. 2014;Accessed December 6, 2018.

42. Politi MC, Kaphingst KA, Kreuter M, Shacham E, Lovell MC, McBride T. Knowledge of health insurance terminology and details among the uninsured. Med Care Res Rev. 2014;71(1):85-98.

43. Levitt L. Why health insurance literacy matters. Jama. 2015;313(6):555556.

44. Politi MC, Kaphingst KA, Liu JE, et al. A Randomized Trial Examining Three Strategies for Supporting Health Insurance Decisions among the Uninsured. Med Decis Making : Int $\mathrm{J}$ Soc Med Decis Mak. 2016;36(7):911-922

45. Zafar SY, Ubel PA, Tulsky JA, Pollak KI. Cost-related health literacy: a key component of high-quality cancer care. J Oncol Pract. 2015;11(3):171-173.

46. Yabroff KR ZJ, Zheng Z, Rai A, Han X. Medical financial hardship among cancer survivors in the United States: what do we know? what do we need to know? Cancer epidemiology, biomarkers \& prevention : a publication of the American Association for Cancer Research, cosponsored by the American Society of Preventive Oncology. 2018;in press.

47. Shankaran V, Leahy T, Steelquist J, et al. Pilot Feasibility Study of an Oncology Financial Navigation Program. J Oncol Pract. 2018;14(2):e122e129.

48. Zafar SY. Financial Toxicity of Cancer Care: It's Time to Intervene. J Natl Cancer Inst. 2016;108(5)

49. Robert Wood Johnson Foundation. Costs of Care: Getting the PatientProvider Conversation Right. https://www.rwjf.org/en/blog/2016/06/ costs_of_care_getti.html. Accessed January 15, 2019.

50. Look KA. Value-based insurance design and medication adherence: opportunities and challenges. Am J Manag Care. 2015;21(1):e78-90.

51. Wherry LR, Miller S. Early Coverage, Access, Utilization, and Health Effects Associated With the Affordable Care Act Medicaid Expansions: A Quasi-experimental Study. Ann Intern Med. 2016;164(12):795-803.

52. Miller S, Wherry LR. Health and Access to Care during the First 2 Years of the ACA Medicaid Expansions. New Engl J Med 2017;376(10):947956.

53. Antonisse L, Garfield R, Rudowitz R, Atiga S. Kaiser Family Foundation. The Effects of Medicaid Expansion under the ACA: Updated Findings from a Literature Review. https://www.kff.org/medicaid/issuebrief/the-effects-of-medicaid-expansion-under-the-aca-updated-findings-from-a-literature-review-september-2017/ 2017. Accessed January 15, 2019.

54. Sarpatwari A, Avorn J, Kesselheim AS. State Initiatives to Control Medication Costs-Can Transparency Legislation Help? New Engl J Med 2016;374(24):2301-2304.

55. National Academy for State Health Policy. State Legislative Action on Pharmaceutical Prices. https://nashp.org/state-legislative-action-onpharmaceutical-prices/. Accessed January 15, 2019.

56. Protection from Surprise Bills and Emergency Services. https://www.dfs. ny.gov/consumer/hprotection.htm. Accessed January 15, 2019.

57. National Conference of State Legislatures. State Family and Medical Leave Laws http://www.ncsl.org/research/labor-and-employment/ state-family-and-medical-leave-laws.aspx. Accessed January 15, 2019.

Publisher's Note: Springer Nature remains neutral with regard to jurisdictional claims in published maps and institutional affiliations. 